\section{Is Methylphenidate-Induced Chorea Responsive to Chlorpromazine?}

To the Editor: Involuntary movements are widely reported to occur with many licit and illicit drugs, particularly with dopaminergic agents. Stimulants such as methylphenidate have rarely induced chorea, mainly after a large dose or chronic administration. ${ }^{1,2}$

\section{Case Report}

A 6-year-old girl was seen for acute involuntary movements. She had psychomotor developmental delay without a definite diagnosis after an extensive unrevealing investigation. As her parents were firstdegree relatives, a genetic basis for her disease was suspected. Clinically, besides late psychological and motor acquisitions, she had discrete macrocephalus, congenital mild ataxia, and hyperactivity. Otherwise healthy, she was not medicated and had no familial history of neurological disease. She had the first $18 \mathrm{mg}$ extended-release methylphenidate pill that morning and went to school, where she was unusually agitated and could not stay quiet, persistently moving the neck, arms, and legs as if she was dancing. Upon examination, she had persistent choreoathetoid movements of orofacial muscles, arms, and legs, with transient dystonic postures of the right arm.
There was no clinical improvement when she was treated with biperiden, Chlorpromazine, $6 \mathrm{mg}$ t.i.d. $(0.25 \mathrm{mg} / \mathrm{kg} /$ day $)$, was attempted at the eighth hour after symptom onset, with immediate decrease of the involuntary movements, which further faded over the next hours leaving the child in the previous neurological state.

\section{Discussion}

Methylphenidate inhibits dopamine reuptake by binding to the dopamine transport complex, ${ }^{1}$ leading to increased synaptic dopamine concentration mainly in the striatum. ${ }^{1}$ This is believed to be the basis of its ability to induce movement disorders. Nevertheless, this was reported mainly after chronic treatment or high doses. ${ }^{1,2}$ In our patient, acute chorea was induced by a single low-dose methylphenidate extended-release pill, probably revealing a dopaminergic system in its limit of normal function, in what can be called a brain primed to dopaminergic challenge.

Chlorpromazine, a widely used antipsychotic agent, acts by dopaminergic receptor blockade. According to this, the possibility of counterbalancing methylphenidate effect on dopamine at the synaptic level seems attractive. However, Volkow et al. ${ }^{3}$ concluded it would be necessary to block over $80 \%$ of dopamine receptors with a neuroleptic before methylphenidate effect could be attenuated. This suggests that (a) probably a more rapid recovery would follow a higher chlorpromazine dose; (b) the observed recovery was chlorpromazine independent, as the half-life of this methylphenidate formulation is 12 hours; or (c) chlorpromazine dose was only sufficient because of previous low-dose methylphenidate exposure. We believe that the immediate response ensuing chlorpromazine prescription argues in favor of a specific role for dopamine receptor antagonists in methylphenidate-induced chorea, justifying further trials in clinical practice.

Álvaro Machado, M.D.

João Cerqueira, M.D., Ph.D.

Margarida Rodrigues, M.D.

Neurology Department, Hospital de São Marcos, Braga, Portugal

João SoARES-Fernandes, M.D. Neuroradiology Department, Hospital de São Marcos, Braga

\section{References}

1. Leonard BE, McCartan D, White J, et al: Methylphenidate: a review of its neuropharmacological, neuropsychological, and adverse clinical effects. Hum Psychopharmacol 2004; 19:151-180

2. Heinrich TW: A case report of methylphenidate-induced dyskinesia. Prim Care Companion J Clin Psychiatry 2002; 4:158-159

3. Volkow ND, Wang GJ, Fowler JS, et al: Dopamine transporter occupancies in the human brain induced by therapeutic doses of oral methylphenidate. Am J Psychiatry 1998; 155:1325-1331 